\title{
Systematic Review \\ Comparing Efficacy and Safety in Catheter Ablation Strategies for Paroxysmal Atrial Fibrillation: A Network Meta-Analysis of Randomized Controlled Trials
}

\author{
Emmanouil Charitakis ${ }^{1, *(D)}$, Silvia Metelli ${ }^{2}$ (D) Lars O. Karlsson ${ }^{1}$, Antonios P. Antoniadis ${ }^{3}$, Ioan Liuba ${ }^{1}$, \\ Henrik Almroth ${ }^{1}$, Anders Hassel Jönsson ${ }^{1}$, Jonas Schwieler ${ }^{4}$, Skevos Sideris ${ }^{5}$, Dimitrios Tsartsalis ${ }^{6}$, \\ Elena Dragioti $^{7,8}$ (D), Nikolaos Fragakis ${ }^{3}$ (D) and Anna Chaimani ${ }^{2}$
}

check for updates

Citation: Charitakis, E.; Metelli, S.; Karlsson, L.O.; Antoniadis, A.P.; Liuba, I.; Almroth, H.; Hassel Jönsson, A.; Schwieler, J.; Sideris, S.; Tsartsalis, D.; et al. Comparing Efficacy and Safety in Catheter Ablation Strategies for Paroxysmal Atrial Fibrillation: A Network Meta-Analysis of Randomized Controlled Trials. Diagnostics 2022, 12, 433. https://doi.org/10.3390/ diagnostics12020433

Academic Editors: Carlo de Asmundis and Maria I. Dorobantu

Received: 14 December 2021

Accepted: 29 January 2022

Published: 9 February 2022

Publisher's Note: MDPI stays neutral with regard to jurisdictional claims in published maps and institutional affiliations.

Copyright: (c) 2022 by the authors Licensee MDPI, Basel, Switzerland. This article is an open access article distributed under the terms and conditions of the Creative Commons Attribution (CC BY) license (https:// creativecommons.org/licenses/by/ $4.0 /)$.
1 Department of Cardiology, Linköping University Hospital, 58185 Linköping, Sweden; lars.o.karlsson@regionostergotland.se (L.O.K.); ioan.liuba@regionostergotland.se (I.L.); Henrik.almroth@regionostergotland.se (H.A.); anders.hassel.jonsson@regionostergotland.se (A.H.J.)

2 Research Center of Epidemiology and Statistics (CRESS-U1153), INSERM, Université de Paris, 75004 Paris, France; silvia.metelli@parisdescartes.fr (S.M.); anna.chaimani@inserm.fr (A.C.)

3 3rd Cardiology Department, Hippokrateion General Hospital, Aristotle University Medical School, 54124 Thessaloniki, Greece; aantoniadis@gmail.com (A.P.A.); fragakis.nikos@googlemail.com (N.F.)

4 Heart and Vascular Theme, Karolinska University Hospital, 17176 Stockholm, Sweden; jonas.schwieler@sll.se

5 Department of Cardiology, Hippokration Hospital, 11527 Athens, Greece; skevos1@otenet.gr

6 Department of Clinical Physiology, Linköping University Hospital, 58185 Linköping, Sweden; dtsartsalis@gmail.com

7 Pain and Rehabilitation Centre, Linköping University Hospital, 58185 Linköping, Sweden; elena.dragioti@liu.se

8 Department of Health, Medicine and Caring Sciences, Linköping University, 58183 Linköping, Sweden

* Correspondence: emmanouil.charitakis@liu.se

Abstract: Although catheter ablation (CA) is an established treatment for paroxysmal atrial fibrillation (PAF), there is no consensus regarding the most efficient CA strategy. The objective of this network meta-analysis (NMA) was to compare the efficacy and safety of different CA strategies for PAF. A systematic search was performed in PubMed, Web of Science, and CENTRAL until the final search date, 5 October 2020. Randomised controlled trials (RCT) comparing different CA strategies and methods for pulmonary vein isolation (PVI) were included. Efficacy was defined as lack of arrhythmia recurrence after CA and safety as any reported complication related to the procedure during a minimum follow-up time of six months. In total, 43 RCTs comparing 11 different CA strategies involving 6701 patients were included. The risk of recurrence was significantly decreased in comparison with PVI with radiofrequency only for the following treatments: PVI with adjuvant ablation (RR: 0.79, CI: 0.65-0.97) and PVI with sympathetic modulation (RR: 0.64, CI: 0.46-0.88). However, PVI with radiofrequency was superior to non-PVI strategies (RR: 1.65, CI: 1.2-2.26). No statistically significant difference was found in safety between different CA strategies. Concerning different PVI strategies, no difference was observed either in efficacy or in safety between tested strategies. This NMA suggests that different PVI strategies are generally similar in terms of efficacy, while PVI with additional ablation or sympathetic modulation may be more effective than PVI alone. This study provides decision-makers with insights into the efficacy and safety of different CA strategies.

Keywords: network meta-analysis; paroxysmal atrial fibrillation; catheter ablation; antiarrhythmic drugs

\section{Introduction}

Atrial fibrillation (AF) is the most common cardiac arrhythmia. In the U.S. alone, the prevalence of AF was estimated to be 5.2 million in 2010, while it is anticipated to double by 2030 [1]. AF constitutes a significant burden for patients and physicians [1], being one of the major causes of stroke, heart failure, and sudden death [2]. 
Patients experiencing short episodes of AF that terminate spontaneously or with intervention within seven days are classified as having paroxysmal AF (PAF) [2,3]. Catheter ablation (CA) and the use of antiarrhythmic drugs (AADs) are the most important heart rhythm (HR) control treatment options for these patients. These treatments have the potential to affect mortality and morbidity outcomes; however, the former has been difficult to prove [4]. Treatment with AADs has been questioned since it has been associated with side effects such as proarrhythmia; the latter hypothesised to explain that rhythm control through AADs does not offer mortality benefits [2]. However, a recent paper reported that early rhythm control therapy through AAD or CA was associated with a lower risk of adverse cardiovascular outcomes in patients with a short history of $\mathrm{AF}$ ( $\leq 1$ year) [5]. Additionally, CA in a recent meta-analysis was associated with lower all-cause mortality and reduced recurrences of atrial arrhythmia compared with AADs [4].

Pulmonary vein isolation (PVI) has been the cornerstone of CA procedures for AF since the seminal observation of the initiation of AF by ectopic beats from the pulmonary veins [6,7]. CA procedures are differentiated by the energy source used, most frequently radiofrequency (RF) and cryothermal energy, as well as the strategy followed, such as PVI, non-PVI, or PVI with adjuvant ablation treatment. While CA is the mainstay HR control strategy in AF patients, the optimal CA strategy is under debate. Different treatment strategies have been suggested aiming at better long-term outcomes with regards to symptom and rhythm control, where many of them are less evaluated and different AF populations targeted. Prior meta-analyses on the topic have been conducted, but they were either inconclusive [8], focused on comparing CA to AADs [4], or compared different energy sources for the isolation of the pulmonary veins [9]. Thus, the need for a meta-analysis comparing the efficacy and safety of different CA strategies is emerging.

Network meta-analysis (NMA) is a statistical method that provides estimates of the relative effects for all available interventions, allowing comparison between every pair of treatments, even when they have not been compared directly in any trial $[10,11]$. NMA is an established method and has been applied in the field of cardiovascular medicine $[12,13]$ and provides a powerful tool for the development of decision-making guidelines at different levels [14]. Thus, by employing the NMA methodology, we sought to compare the efficacy and safety of different CA strategies for the treatment of PAF.

\section{Materials and Methods}

\subsection{Study Design}

This NMA is reported following the Preferred Reporting Items for Systematic Reviews and Meta-analyses (PRISMA) extension statement for NMA [15] (Table S1 in Section S1 in Supplement). This NMA is based on previously published data; thus, it does not require ethical approval or consent to participate. The study protocol was registered in the prospective registry of systematic reviews, PROSPERO with registration number CRD42020169494, and has been published previously [16].

\subsection{Eligibility Criteria and Type of Interventions}

We included randomised controlled trials (RCTs), comparing different CA strategies for PAF in adults $[2,17]$. Studies that included patients with prior ablation (catheter, surgical or atrioventricular node ablation) or used a study design other than an RCT [16] were excluded.

The primary intervention of interest included CA strategies such as PVI, non-PVI approaches, PVI and adjuvant ablation treatments, PVI and sympathetic modulation, different PVI-strategies such as PVI RFA, PVI with cryoballoon ablation (CBA), laserballoon ablation (LBA), or phase duty-cycled radiofrequency (PRF). All interventions are presented in Table 1 and Table S2 in Section S2 in the Supplement. 
Table 1. Interventions included in NMA (and their abbreviations).

\begin{tabular}{cc}
\hline $\begin{array}{c}\text { Abbreviations of Interventions } \\
\text { Included in NMA }\end{array}$ & Interventions Included in the NMA \\
\hline CBA PVI & $\begin{array}{c}\text { Pulmonary vein isolation with Cryoballoon ablation } \\
\text { Pulmonary vein isolation with Cryoballoon ablation } \\
\text { with adjuvant radiofrequency ablation }\end{array}$ \\
HBA PVI & Pulmonary vein isolation with hot balloon ablation \\
LBA PVI & Pulmonary vein isolation with laser balloon ablation \\
Non-PVI & Nonpulmonary vein isolation strategies such as ganglia \\
PVI RFA & plexi or electrocardiogram ablation \\
PVI + sympathetic modulation & $\begin{array}{c}\text { Pulmonary vein isolation with radiofrequency ablation } \\
\text { Pulmonary vein isolation with sympathetic modulation } \\
\text { such as ganglia plexi ablation or renal denervation }\end{array}$ \\
PVI + adjuvants & $\begin{array}{c}\text { Pulmonary vein isolation and adjuvant ablation such as } \\
\text { additional lines or/and superior vena cava isolation } \\
\text { or /and posterior box isolation or/and } \\
\text { electrocardiogram-based ablation }\end{array}$ \\
PVI partly & Isolation of some pulmonary veins \\
PVI + ridge & Pulmonary vein isolation and ridge ablation \\
PVI + trig & Pulmonary vein isolation and trigger ablation \\
PRF RFA & Phase duty-cycled radiofrequency ablation for the \\
& isolation of the pulmonary veins \\
\hline
\end{tabular}

\subsection{Search Strategy, Study, and Data Collection}

The investigators (EC and DT) performed a comprehensive screening guided by the inclusion criteria to identify eligible studies (the search code is presented in Section S3, Supplement). We searched for relevant articles using PubMed, the Cochrane Central Register of Controlled Trials, and the Web of Science to the final search date, the 5 October 2020. Finally, references of previously published systematic reviews and included RCTs were screened for additional eligible studies.

The investigators (EC and DT) independently reviewed the titles and abstracts retrieved from the screening. For eligibility, inclusion criteria should be met, and the investigators should agree. Studies that were excluded (ineligible) were evaluated by both reviewers who agreed that they did not meet the inclusion criteria. In cases of disagreement, a third member was called in to adjudicate (ED). The full text of the remaining articles was obtained for eligibility control, and investigators (EC and DT) read each article and performed the data abstraction independently. Any disagreements were resolved by consultation with a third reviewer (ED) [16].

All data were summarised based on study characteristics (first author's name, publication year, enrolment period, trial design), patient characteristics (age, sex, type of $\mathrm{AF}$, background factors, etc.), intervention-related data (CA approach, fluoroscopy time, blanking period, follow-up time, methods used for the detection of possible recurrences, etc.), and outcome measures. The original authors were contacted for data requests when missing data was evident.

\subsection{Outcomes}

\subsubsection{Primary Outcomes}

Efficacy outcome: Recurrence of AF or atrial tachycardia (AT) at $\geq 6$ months after CA for AF in patients with PAF with a minimum duration of $30 \mathrm{~s}$ recorded on implantable loop recorder (ILR), pacemaker, defibrillator, ECG, or ambulatory ECG.

Safety: All reported complications related to the procedure (periprocedural or occurred during the follow-up).

\subsubsection{Secondary Outcomes}

The secondary outcomes included: 
Procedural time: defined as the time (measured in minutes) from the vascular access to the end of the procedure

All-cause mortality: from randomisation until the end of study follow-up.

\subsection{Quality Assessment}

The quality of the included RCTs was rated by the Cochrane Collaboration risk of bias (RoB) tool for RCTs (RoB V.2) [18]. RoB V.2 is structured into domains of bias, and a proposed decision about the $\operatorname{RoB}$ is generated based on answers to domain-relevant signalling questions. A decision can be of 'low' or 'high' RoB or raise 'some concerns' [18]. The way missing data were treated has been previously discussed [16] (more details are given in Section S4 in the Supplement).

\subsection{Evaluation of Clinical Assumptions and Transitivity}

Qualitative comparisons of study and population characteristics across trials were conducted to assess whether these were sufficiently homogeneous to be synthesised together. Transitivity is the fundamental assumption of NMA and refers to the validity of carrying out indirect comparisons between treatments via one or more intermediate comparators. This means that, for any three treatments $A, B$, and $C$, if direct evidence exists for A vs. B and A vs. C, we can indirectly get the effect of B vs. C via A as (effect of A vs. C)-(effect of A vs. B). We examined transitivity graphically by comparing the distribution of several clinical and demographical variables (such as age, sex, hypertension, structural heart disease (SHD), coronary artery disease (CAD), left atrial dimensions, etc.) that could act as effect modifiers across treatment comparisons.

\subsection{Data Synthesis and Evaluation of Statistical Assumptions}

For each comparison between at least two studies or more, we performed randomeffects pairwise, and network meta-analysis (NMA) [19] using R software (R version 4.0.2, netmeta package, version 6.6-6) to estimate summary risk ratios for efficacy and safety (RRs), and summary mean differences (MDs) for procedural time (minutes). For ranking treatments in this NMA, we used a frequentist analogue to the surface under the cumulative ranking curve (SUCRA), the P-score.

In the NMA, we assumed a common heterogeneity parameter to be shared across comparisons within an outcome, and we estimated the treatment hierarchy for the primary outcomes using P-scores, which represent the average extent of certainty for each intervention to be better than the competing ones [20].

Statistical heterogeneity has been studied using visual inspection of the forest plots, along with the magnitude of the between-study variance $\left(\tau^{2}\right)$ [21] while statistical inconsistency (i.e., the disagreement of direct and indirect evidence) was evaluated with: (a) the side-splitting method and (b) the design-by-treatment interaction model. The former assesses inconsistency for every comparison, while the latter provides a global test of the entire network.

\subsection{Small-Study Effects and Additional Analyses}

For each outcome, the presence of small-study effects was evaluated by comparisonadjusted funnel plots for all active strategies against control (PVI) [10,22]. Prespecified subgroup analyses were performed based on AF detection device, follow-up duration, and AAD or repeat ablation during follow-up. Possible sources of heterogeneity with regards to publication year were assessed through a post hoc subgroup analysis. If evidence of heterogeneity or inconsistency was found, metaregressions followed to investigate whether clinical demographical or other methodological characteristics were acting as effect modifiers. The impact of each covariate was assessed in independent univariate analyses, retaining only those variables for which data were available for at least 10 studies. Moreover, sensitivity analyses were performed for the primary outcomes, excluding studies with high RoB (as reported in the RoB section) and studies using nonirrigated RFA catheters. We also 
performed a sensitivity analysis, including studies involving antiarrhythmic drugs (AADs). Finally, evaluation of the overall credibility of the evidence was carried out through the CINeMA framework (https: / / cinema.ispm.Unibe.ch; last accessed: 2 December 2021) [23] (More details concerning the methodology of the trial can be found in Sections S5-S13 in the Supplement).

\section{Results}

\subsection{Characteristics of the Included Studies and Risk of Bias Assessment}

The literature search identified 5786 articles, of which 343 were considered eligible after the title and abstract review process. After a full-text review, 43 RCTs performed between 2003-2020 met the criteria for inclusion in the NMA (Figure 1), comparing 11 different CA strategies. Efficacy was reported by all studies, safety, and procedural time by 36 studies $(84 \%)$ and $35(81 \%)$ studies, respectively (Figure 2). Five RCTs had a high risk of bias (RoB V2 tool) (Section S5 in the Supplement). Deviations from the original protocol are presented in Section S6 in the Supplement.
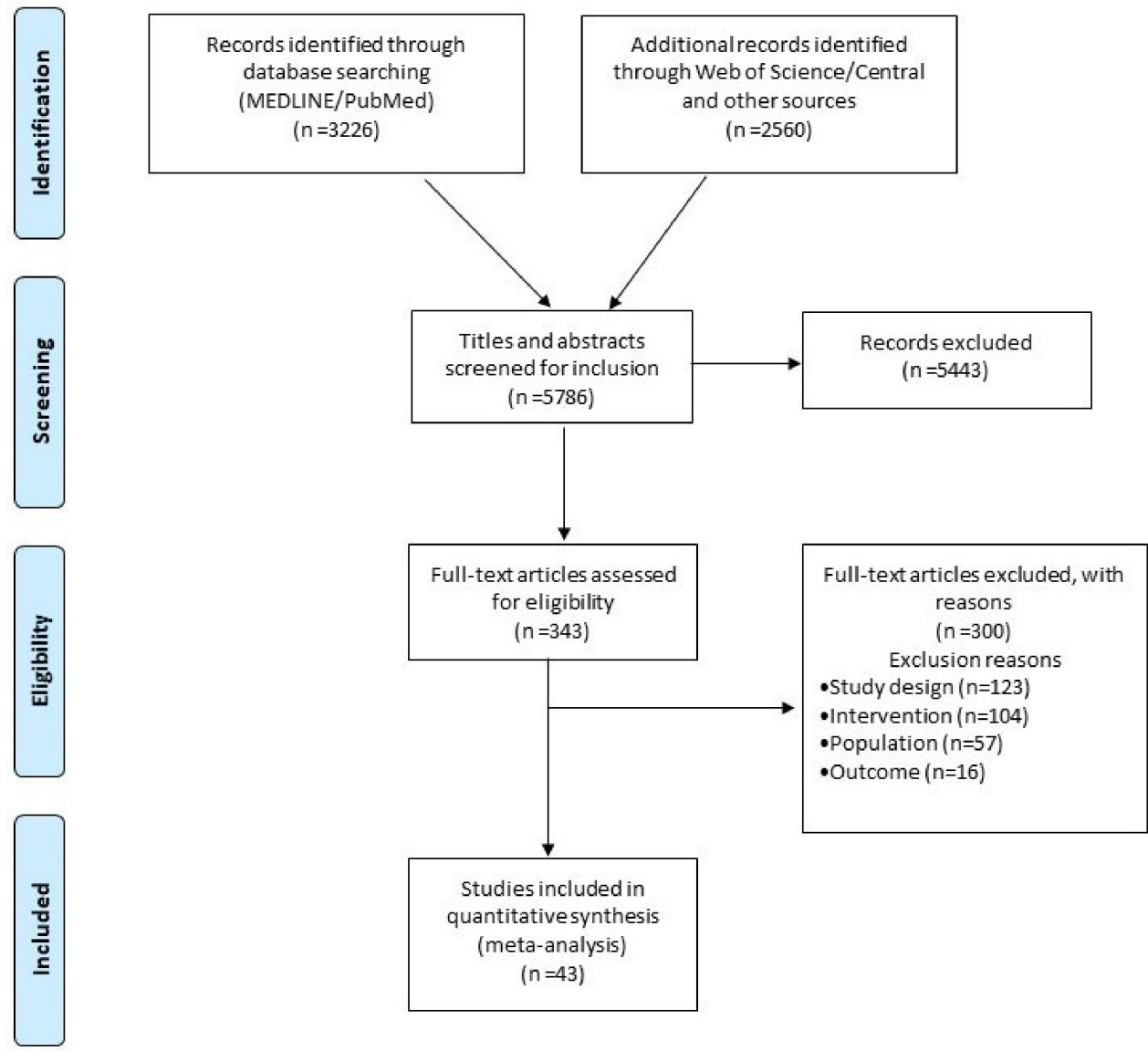

Figure 1. Prisma Flow chart diagram.

\subsection{Evaluation of Clinical Assumptions and Transitivity}

Of the 6701 randomised patients, $69 \%$ were males, and the mean age was 58 years. The definition of effectiveness used in the included studies varied. This was due to different blanking periods and whether AADs or reablation were allowed according to the study protocol. We addressed this through sensitivity analyses. No important clinical differences in the distributions of most effect modifiers across different AF comparisons were observed for the majority of the characteristics analysed. Due to very limited available data for SHD and CAD, transitivity could not be properly evaluated concerning these two characteristics (Section S6 in the Supplement). 
A

Network diagram for efficacy
Network diagram for safety
Network diagram for procedural time
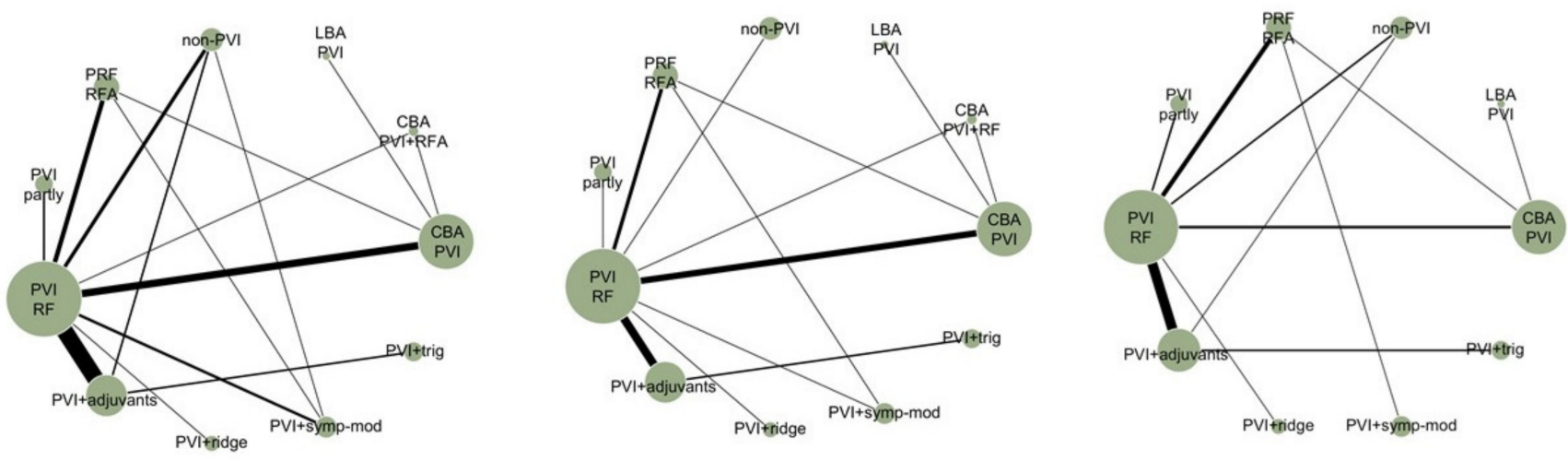

Figure 2. Network plots for efficacy (A), safety (B), and procedural time (C). Each treatment is represented as a node, and an edge is drawn between two nodes if direct evidence is available. The size of each node is proportional to the number of studies available in the corresponding comparison.

\subsection{Relative Effects and Ranking of Treatments}

\subsubsection{Primary Outcomes}

Results from NMA evidence showed that non-PVI strategies (non-PVI) were statistically inferior to PVI with radiofrequency energy (PVI RF) (RR for non-PVI vs. PVI RF: 0.62, 95\%CI: 0.44-0.89) (Figures 3 and 4 and Section S7 in the Supplement).

A

Forest plot for efficacy
B

Forest plot for safety
C

Forest plot for procedural time
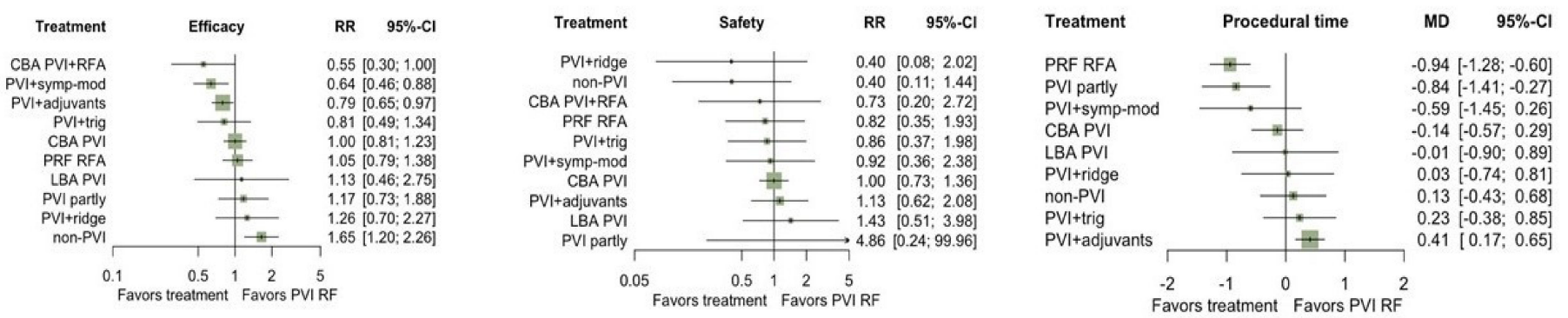

Figure 3. Forest plots for efficacy (A), safety (B), and procedural time (unit: minutes) (C) compared with PVI RF reporting the network meta-analysis RRs with their 95\% CIs. Abbreviations: CBA: Cryoballoon ablation, HBA: Hot-balloon ablation, LBA: Laser-balloon ablation, PVI: Pulmonary vein isolation, RFA: radiofrequency ablation, trig: trigger ablation, PRF: Phase duty-cycled radiofrequency ablation.

Strategies combining PVI with a) either adjuvant ablation (PVI+adjuvants) or b) sympathetic modulation (PVI+symp-mod) were significantly more efficient than PVI by RF as a stand-alone treatment (RR:0.79, 95\%CI: 0.65-0.97, and RR: 0.64, 95\%CI: 0.46-0.88), respectively (Figures $3 \mathrm{~A}$ and 4 ). Non-PVI strategies were statistically less efficacious than PVI RF. No significant difference was found between PVI RF and CBA PVI (RR:1, 95\%CI: $0.81-1.23)$. 


\begin{tabular}{|c|c|c|c|c|c|c|c|c|c|c|}
\hline PVI RF & $\begin{array}{c}1.00 \\
(0.74 ; 1.37)\end{array}$ & $\begin{array}{c}0.70 \\
(0.25 ; 1.95)\end{array}$ & $\begin{array}{c}1.21 \\
(0.52 ; 2.84)\end{array}$ & $\begin{array}{c}0.21 \\
(0.01 ; 4.24)\end{array}$ & $\begin{array}{c}1.36 \\
(0.37 ; 5.04)\end{array}$ & $\begin{array}{c}1.08 \\
(0.42 ; 2.79)\end{array}$ & $\begin{array}{c}0.88 \\
(0.48 ; 1.62)\end{array}$ & $\begin{array}{c}1.16 \\
(0.50 ; 2.68)\end{array}$ & $\begin{array}{c}2.50 \\
(0.49 ; 12.63)\end{array}$ & $\begin{array}{c}2.48 \\
(0.69 ; 8.88)\end{array}$ \\
\hline $\begin{array}{c}1.00 \\
(0.81 ; 1.23)\end{array}$ & CBA PVI & $\begin{array}{c}1.00 \\
(0.74 ; 1.37)\end{array}$ & $\begin{array}{c}0.70 \\
(0.25 ; 1.95)\end{array}$ & $\begin{array}{c}1.21 \\
(0.52 ; 2.84)\end{array}$ & $\begin{array}{c}0.21 \\
(0.01 ; 4.24)\end{array}$ & $\begin{array}{c}1.36 \\
(0.37 ; 5.04)\end{array}$ & $\begin{array}{c}1.08 \\
(0.42 ; 2.79)\end{array}$ & $\begin{array}{c}0.88 \\
(0.48 ; 1.62)\end{array}$ & $\begin{array}{c}1.16 \\
(0.50 ; 2.68)\end{array}$ & $\begin{array}{c}2.50 \\
(0.49 ; 12.63)\end{array}$ \\
\hline $\begin{array}{c}0.88 \\
(0.36 ; 2.15)\end{array}$ & $\begin{array}{c}0.89 \\
(0.37 ; 2.10)\end{array}$ & LBA PVI & $\begin{array}{c}1.73 \\
(0.47 ; 6.40)\end{array}$ & $\begin{array}{c}0.29 \\
(0.01 ; 7.17)\end{array}$ & $\begin{array}{c}1.95 \\
(0.38 ; 9.95)\end{array}$ & $\begin{array}{c}1.55 \\
(0.38 ; 6.23)\end{array}$ & $\begin{array}{c}1.26 \\
(0.38 ; 4.15)\end{array}$ & $\begin{array}{c}1.66 \\
(0.44 ; 6.23)\end{array}$ & $\begin{array}{c}3.57 \\
(0.53 ; 24.28)\end{array}$ & $\begin{array}{c}3.55 \\
(0.69 ; 18.19)\end{array}$ \\
\hline $\begin{array}{c}0.95 \\
(0.72 ; 1.26)\end{array}$ & $\begin{array}{c}0.96 \\
(0.69 ; 1.32)\end{array}$ & $\begin{array}{c}1.08 \\
(0.43 ; 2.72)\end{array}$ & PRF RFA & $\begin{array}{c}1.73 \\
(0.47 ; 6.40)\end{array}$ & $\begin{array}{c}0.29 \\
(0.01 ; 7.17)\end{array}$ & $\begin{array}{c}1.95 \\
(0.38 ; 9.95)\end{array}$ & $\begin{array}{c}1.55 \\
(0.38 ; 6.23)\end{array}$ & $\begin{array}{c}1.26 \\
(0.38 ; 4.15)\end{array}$ & $\begin{array}{c}1.66 \\
(0.44 ; 6.23)\end{array}$ & $\begin{array}{c}3.57 \\
(0.53 ; 24.28)\end{array}$ \\
\hline $\begin{array}{c}0.85 \\
(0.53 ; 1.36)\end{array}$ & $\begin{array}{c}0.85 \\
(0.51 ; 1.43)\end{array}$ & $\begin{array}{c}0.96 \\
(0.35 ; 2.63)\end{array}$ & $\begin{array}{c}0.89 \\
(0.52 ; 1.54)\end{array}$ & PVI partly & $\begin{array}{c}6.61 \\
(0.25 ; 178.37)\end{array}$ & $\begin{array}{c}5.26 \\
(0.22 ; 125.15)\end{array}$ & $\begin{array}{c}4.29 \\
(0.20 ; 93.85)\end{array}$ & $\begin{array}{c}5.65 \\
(0.25 ; 130.27)\end{array}$ & $\begin{array}{c}12.14 \\
(0.39 ; 375.21)\end{array}$ & $\begin{array}{c}12.06 \\
(0.45 ; 321.04)\end{array}$ \\
\hline $\begin{array}{c}1.81 \\
(1.00 ; 3.30)\end{array}$ & $\begin{array}{c}1.82 \\
(0.99 ; 3.32)\end{array}$ & $\begin{array}{c}2.05 \\
(0.71 ; 5.89)\end{array}$ & $\begin{array}{c}1.90 \\
(0.99 ; 3.66)\end{array}$ & $\begin{array}{c}2.13 \\
(0.99 ; 4.56)\end{array}$ & $\begin{array}{c}\text { CBA PVI } \\
+ \text { RFA }\end{array}$ & $\begin{array}{c}0.80 \\
(0.16 ; 4.00)\end{array}$ & $\begin{array}{c}0.65 \\
(0.15 ; 2.75)\end{array}$ & $\begin{array}{c}0.86 \\
(0.18 ; 4.04)\end{array}$ & $\begin{array}{c}1.84 \\
(0.23 ; 14.73)\end{array}$ & $\begin{array}{c}1.82 \\
(0.29 ; 11.33)\end{array}$ \\
\hline$\frac{1.57}{(1.14 ; 2.18)}$ & $\frac{1.57}{(1.07 ; 2.31)}$ & $\begin{array}{c}1.78 \\
(0.69 ; 4.58)\end{array}$ & $\frac{1.65}{(1.11 ; 2.45)}$ & $\frac{1.85}{(1.04 ; 3.27)}$ & $\begin{array}{c}0.87 \\
(0.44 ; 1.71)\end{array}$ & $\begin{array}{c}\text { PVI+ } \\
\text { symp-mod }\end{array}$ & $\begin{array}{c}0.82 \\
(0.26 ; 2.51)\end{array}$ & $\begin{array}{c}1.07 \\
(0.30 ; 3.80)\end{array}$ & $\begin{array}{c}2.31 \\
(0.35 ; 15.07)\end{array}$ & $\begin{array}{c}2.29 \\
(0.47 ; 11.21)\end{array}$ \\
\hline$\frac{1.26}{(1.03 ; 1.54)}$ & $\begin{array}{c}1.26 \\
(0.95 ; 1.69)\end{array}$ & $\begin{array}{c}1.43 \\
(0.57 ; 3.55)\end{array}$ & $\begin{array}{c}1.32 \\
(0.94 ; 1.86)\end{array}$ & $\begin{array}{c}1.48 \\
(0.89 ; 2.47)\end{array}$ & $\begin{array}{c}0.70 \\
(0.37 ; 1.31)\end{array}$ & $\begin{array}{c}0.80 \\
(0.55 ; 1.17)\end{array}$ & $\begin{array}{c}\text { PVI+ } \\
\text { adjuvants }\end{array}$ & $\begin{array}{c}1.32 \\
(0.74 ; 2.33)\end{array}$ & $\begin{array}{c}2.83 \\
(0.50 ; 15.96)\end{array}$ & $\begin{array}{c}2.81 \\
(0.68 ; 11.53)\end{array}$ \\
\hline $\begin{array}{c}1.23 \\
(0.75 ; 2.02)\end{array}$ & $\begin{array}{c}1.23 \\
(0.72 ; 2.11)\end{array}$ & $\begin{array}{c}1.39 \\
(0.50 ; 3.85)\end{array}$ & $\begin{array}{c}1.29 \\
(0.73 ; 2.28)\end{array}$ & $\begin{array}{c}1.44 \\
(0.73 ; 2.86)\end{array}$ & $\begin{array}{c}0.68 \\
(0.31 ; 1.48)\end{array}$ & $\begin{array}{c}0.78 \\
(0.43 ; 1.41)\end{array}$ & $\begin{array}{c}0.97 \\
(0.62 ; 1.54)\end{array}$ & PVI+trig & $\begin{array}{c}2.15 \\
(0.35 ; 13.29)\end{array}$ & $\begin{array}{c}2.13 \\
(0.47 ; 9.79)\end{array}$ \\
\hline $\begin{array}{c}0.80 \\
(0.44 ; 1.44)\end{array}$ & $\begin{array}{c}0.80 \\
(0.43 ; 1.49)\end{array}$ & $\begin{array}{c}0.90 \\
(0.31 ; 2.61)\end{array}$ & $\begin{array}{c}0.83 \\
(0.43 ; 1.60)\end{array}$ & $\begin{array}{c}0.93 \\
(0.44 ; 1.99)\end{array}$ & $\begin{array}{c}0.44 \\
(0.19 ; 1.02)\end{array}$ & $\frac{0.51}{(0.26 ; 0.99)}$ & $\begin{array}{c}0.63 \\
(0.34 ; 1.17)\end{array}$ & $\begin{array}{c}0.65 \\
(0.30 ; 1.40)\end{array}$ & PVI+ridge & $\begin{array}{c}0.99 \\
(0.13 ; 7.80)\end{array}$ \\
\hline$\frac{0.61}{(0.44 ; 0.83)}$ & $\frac{0.61}{(0.42 ; 0.89)}$ & $\begin{array}{c}0.69 \\
(0.27 ; 1.76)\end{array}$ & 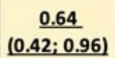 & $\begin{array}{c}0.71 \\
(0.40 ; 1.26)\end{array}$ & $\frac{0.33}{(0.17 ; 0.66)}$ & $\frac{0.39}{(0.25 ; 0.58)}$ & $\frac{0.48}{(0.34 ; 0.68)}$ & $\frac{0.49}{(0.28 ; 0.88)}$ & $\begin{array}{c}0.76 \\
(0.39 ; 1.49)\end{array}$ & non-PVI \\
\hline
\end{tabular}

Figure 4. Risk ratios (RRs) for efficacy (lower triangle) and safety (upper triangle) with 95\% CIs from network meta-analysis for 11 AF strategies available. Each cell is coloured by the certainty of evidence assessed for each comparison with CINeMA and classified as high (in green), moderate (in blue), low (in yellow). Abbreviations: CBA: cryoballoon ablation, HBA: hot balloon ablation, LBA: laser balloon ablation, PVI: pulmonary vein isolation, RFA: radiofrequency ablation, trig: trigger ablation, PRF: phase duty-cycled radiofrequency ablation.

Regarding safety, no differences between CA strategies were evident from the NMA results (Figure 3B and Table S4 in Section S7 in the Supplement), nor a significant comparison between active treatments (Figure 4). Nonetheless, findings were quite imprecise for all comparisons, and thus no conclusive evidence could be supported.

According to the p-scores, PVI with adjuvants and PVI with symp-mod combinations of PVI appeared to be among the most effective treatments in patients with PAF (Section S7 in the Supplement), while the significant uncertainty in safety estimation hinders our confidence in conclusions about ranking for this outcome.

\subsubsection{Secondary Outcome}

According to NMA results, PVI with adjuvant ablation was more time-consuming, compared with PVI RF (MD:0.41, 95\%CI: 0.17-0.65 min), while PRF RFA [MD: -0.94, 95\%CI: $-1.28 ;-0.60 \mathrm{~min}]$ and partial PVI [MD $=-0.84,95 \% \mathrm{CI}:-1.41 ;-0.27 \mathrm{~min}]$ were found to have shorter procedural time in comparison with PVI RF (Figure 3C). Moreover, none of the comparisons between active strategies performed better when contrasted with another active strategy (Table S5 in Section S7 in the Supplement).

All-cause mortality was not analysed due to the high prevalence of studies with zero events in both arms.

\subsection{Assessment of Heterogeneity and Inconsistency}

Network heterogeneity was low to moderate $\left(\tau^{2}=0.056\right.$ for efficacy, $\tau^{2}=0$ for safety, $\tau^{2}=0.15$ for procedural time). The overall design-by-treatment interaction test for inconsistency did not show any concerns of inconsistency for safety and procedural time but raised 'some' concern for efficacy (Section S8 in the Supplement). Similarly, the node-splitting method identified a few comparisons with 'some' concern of inconsistency for efficacy (Section S8, Supplement). However, in both models, this may be caused by a lack of statistical power in the tests since only a small number of studies per comparison inform the indirect estimation. 


\subsection{Small-Study Effects and Additional Analyses}

From the graphical assessment of comparison-adjusted funnel plots, small-study effects did not appear to operate for any outcome. Even though the funnel plot of safety appears slightly less symmetrical, this might be attributable to the considerable imprecision observed in this outcome. Noteworthy, the procedural time funnel plot suggested the presence of a rather significant heterogeneity (Section S9 in the Supplement). This phenomenon can, to some extent, be explained by selective reporting.

Subgroup analyses showed favourable effects, i.e., more precise estimates (Section S10, Supplement) for some strategies; ECGs with longer recording times and not allowing AADs during follow-up. Conclusive evidence was not possible for follow-up time due to a large imbalance regarding group size. To inspect for potential causes of heterogeneity and inconsistency, we performed metaregression for efficacy. In metaregression, age and CAD were associated with a reduction in the heterogeneity of $14.7 \%$ and $30.7 \%$, respectively, while the coefficients for all other variables were not significant and close to zero (Section S11 in the Supplement).

Sensitivity analyses excluding studies with a high risk of bias, or RCTs with nonirrigational RFA catheters, or including RCTs involving antiarrhythmic drugs (AAD) did not result in any significant risk change (Section S12 in the Supplement).

The sensitivity analysis including AADs included three additional RCTs (47 RCTs, $n=7633,68 \%$ males, mean age 56 years). No significant change was found compared to the main analysis. Additionally, the majority of CA strategies, including PVI RF, CBA PVI, and PVI with adjuvants, were associated with a lower risk of recurrence when compared with AADs, RRs range from 0.22 (95\%CI: 0.1,0.51) to 0.47 (95\%CI: 0.23,0.98) (Section S12 in the Supplement).

\subsection{Overall Quality of Evidence}

According to the CINeMA evaluation (credibility of the evidence), confidence was mostly low for efficacy and moderate for safety. In both networks, the reasons for downgrading to moderate or low certainty were mainly related to the presence of significant concerns in imprecision, either alone or accompanied by some concerns in incoherence or indirectness. More details and concrete rules for downgrading are provided in Section S13 in the Supplement.

\section{Discussion}

Catheter ablation is an established treatment for the prevention of recurrences in patients with $\mathrm{AF}$ [2]. CA is generally recommended after failure of AADs, while recent guidelines [2] suggest that CA may be considered as first-line therapy in patients with PAF [2,24]. Regarding the recommended CA strategy for patients with PAF, PVI either in a point-by-point manner or as a one-shot device has been prioritised [2]. However, even if the results after PVI in patients with AF are satisfactory, SR in all PAF patients is not guaranteed $[25,26]$. This NMA explored and analysed existing data from 43 RCTs concerning 6701 patients to provide additional information about the most optimal CA strategy in patients with PAF.

The main findings of this NMA were:

- Based on the existing evidence, non-PVI strategies appear to be inferior in efficacy compared with the majority of PVI strategies.

- Different PVI strategies were found to be similarly effective.

- Different ablation strategies seem to be similar in terms of safety.

- Performing additional ablation to PVI is time-consuming, while there is no difference concerning procedural duration between the most used PVI strategies.

- $\quad$ All CA strategies except for non-PVI strategies and LBA appear to be superior to AADs. 


\subsection{Differences in Efficacy between Various CA Strategies}

Pulmonary vein isolation is the strategy that gave a boost to CA for AF [2] and is the reason why CA has been established as the best option for HR control of AF. Non-PVI strategies have been tested against PVI in RCTs [27,28]. However, these studies are of small size compared with other CA trials [29] and include predominantly male participants. Thus, data from these studies may overestimate the efficacy of PVI. In the present study, we were able to confirm that CA strategies, including PVI, are superior in efficacy to non-PVI strategies.

Among the different methods used to achieve PVI, the first to be introduced was the use of radiofrequency applied in a point-by-point manner [6,30]. However, the complexity of RFA has limited the availability of CA to a few specialised centres, while the need for more simplified PVI techniques has been growing [29]. In recent years, single-shot devices for PVI have been introduced to meet this need, mainly in the form of balloon-based catheter ablation technologies. The CBA and the LBA systems are the main representatives of this category showing excellent efficacy and safety in some trials even when compared with RFA [29,31,32]. Our data, consistent with previous studies, did not detect strong evidence of superiority with regards to efficacy in one technology over the other $[29,33,34]$. However, a recent NMA by Gupta et al. [14] showed that PVI using RF combined with ablation index technology was superior in terms of efficacy compared with other options, such as CBA. This result is in contrast with our results. Nevertheless, we argue that the results of Gupta et al. should be treated with caution, as the authors included observational studies that raise the risk of bias, and the network was sparse.

Achieving long-term pulmonary vein isolation, either with a single shot device or a point-by-point manner, does not guarantee long-term freedom from atrial arrhythmia recurrence. In a study by Dukkipati et al., the reported AF recurrence rate one year after CA was $29 \%$ despite proven permanent PVI [35]. The reasons behind the lack of sustained response to PVI are not clear, but the existence of triggers outside the PV region has been shown to play an important role in some observational studies [36,37]. Hence, ablation of nonpulmonary vein triggers in specific regions such as the inferior mitral annulus, the interatrial septum, and the superior vena cava $[25,38,39]$ can possibly add efficacy to PVI as a stand-alone therapy. Other CA strategies combined with PVI, such as posterior wall isolation (PWI), have shown promising results, especially in patients with persistent AF, but RCTs comparing PVI to PVI and PWI generated conflicting results [40]. Moreover, a subgroup analysis (Section S10, analysis 4) showed that the statistical superiority of PVI+adjuvant therapy compared with PVI RF is not supported by the RCTs with a publication year $\geq 2011$.

Furthermore, autonomic modulation by, for example, GP as a complementary therapy to PVI, can improve CA's efficacy, possibly by ablation of complex electrical activity areas [41]. Even though extensive wide area circumferential ablation of the pulmonary veins may have benefits beyond PVI, including concomitant ganglionated plexus modification, the use of a more dedicated strategy for the autonomic modulation, such as GP ablation or renal denervation, can benefit patients with PAF [26,41,42]. However, the lack of a sensitive and specific method for GP identification should be taken under consideration [7].

Taking these conclusions together, our study suggests that there is a place to consider additional ablation to the PVI strategy in patients with PAF. However, an individualised approach concerning the CA strategy is needed.

\subsection{Safety}

Even though complication rates regarding $\mathrm{CA}$ of $\mathrm{AF}$ are low, they remain a major concern for both patients and doctors. Accordingly, the aim of developing novel technologies in this field has been to improve the safety profile of CA as well as to enhance its efficacy.

The overall incidence of reported complications in this NMA was $<6 \%$, with a death rate of $<1 \%$. These complication rates are in line with previously published studies, including a worldwide survey $[43,44]$. Many RCTs included in this NMA reported a $0 \%$ mortality 
rate from randomisation to the end of follow-up. This was the reason why the secondary endpoint of all-cause mortality was unable to be processed.

The low incidence of complications observed in our NMA remained the same regardless of the CA strategy followed. This data may allow the electrophysiologist to focus on the best suitable method to enhance the efficacy of CA without being hindered by thoughts of taking an additional risk with a certain ablation strategy. However, it is crucial to acknowledge that most RCTs are performed by high volume academic centres, a fact that can lead to underestimation of the complication risk $[43,45]$.

\subsection{CA Strategies Compared with AADs}

Early intervention in the course of AF by the implementation of AAD therapy or CA can limit its evolution by interrupting various pathophysiological changes [46,47]. Previous RCTs and meta-analyses are showing that arrhythmia recurrences were significantly less frequent in the case of specific CA strategies compared with AADs, especially in patients with PAF $[4,32,48]$. These data concur with the results from the sensitivity analysis, including AADs as a comparison arm presented in the present NMA. The only PVI strategy that failed to show superiority to AADs was LBA. This finding can be possibly explained by the lack of evidence when comparing LBA with AADs (no RCTs directly comparing LBA with AADs and only one RCT comparing LBA with CBA [31]).

\subsection{Procedural Time}

Single-shot PVI strategies were introduced in order to shorten procedural duration compared with point-by-point isolation of the pulmonary veins [29,49]. However, in our NMA, PVI by RFA and PVI with balloon devices did not differ in matters of procedural duration. This countertendency can be possibly explained due to different populations included and the evolution of RF techniques in the last five years.

As expected, the addition of adjuvant ablation therapy to PVI was more time-consuming compared with PVI as stand-alone.

\subsection{Strengthens and Limitation}

This NMA, comparing not only strategies for the PVI but all the available CA strategies for patients with PAF, is the first of its kind. It has the advantage of including 43 RCTs and more than 6701 patients providing the medical society with highly comprehensive results owing to the robustness of the statistical method used. The synthesis of the large number of included RCTs, performed in centres around the world, in combination with the opportunity of incorporating direct and indirect comparisons by the use of NMA, led to the interesting results previously discussed and enhanced the generalizability and applicability of our results to real-world scenarios.

However, our study, as every other meta-analysis, shares the limitations of the original studies. The existence of RCTs with a high risk of bias increases the risk of bias of the meta-analysis. Patients included in the original studies are assumed to have been sampled from the same theoretical pool of patients. Heterogeneity across studies is inevitable, as different methods are used across the original studies (i.e., for the detection of arrhythmia, blanking periods used, and the allowance of antiarrhythmic drugs during the follow-up varied). Additionally, the nature of the intervention can also impose heterogeneity as its efficacy may also depend on unmeasurable characteristics. In the case of the strategy arm of PVI with adjuvant therapies, many different extra ablation strategies have been included in combination with PVI, such as additional lines and superior vena cava isolation or posterior box isolation and electrocardiogram-based ablation. Thus, owing to the large heterogeneity, it is difficult to give a definite conclusion about this group's superiority to PVI. Finally, it can be observed that the networks were quite sparse, in particular for safety and procedural time, making the results more difficult to interpret and the conclusions drawn more uncertain. 


\section{Conclusions}

Overall, different PVI strategies were found to be similarly effective, while PVI with additional ablation therapy or autonomic modulation could increase the efficacy compared with PVI alone. Regarding CA safety, there was no observed difference between different strategies. CA of patients with PAF was statistically more efficient than AAD-therapy regardless of the CA strategy followed, except for non-PVI strategies and LBA. In summary, this NMA provides decision-makers with global and up-to-date evidence about the efficacy and safety of different CA strategies. The combination of these results and an individualised approach depending on patients' needs and risk factors can lead to improved outcomes for PAF patients.

Supplementary Materials: The following are available online at https:/ /www.mdpi.com/article/10 .3390 / diagnostics12020433/s1. Sections S1-S13. References [16,18,25-29,31,33,34,39,41,42,48,50-83] are cited in the supplementary materials.

Author Contributions: Conceptualization, E.C., S.M., A.C.; methodology, E.C., S.M., and A.C.; data curation, E.C., D.T., S.M., A.C., and E.D.; formal analysis, S.M. and A.C.; validation, A.C.; E.C.; L.O.K., and N.F.; writing—original draft, E.C., S.M., and H.A. writing—review and editing, E.C., S.M., L.O.K., A.H.J., I.L., H.A., A.P.A., N.F., S.S., J.S., D.T., E.D., and A.C. All authors commented on different versions of the article. All authors have read and agreed to the published version of the manuscript.

Funding: This research received no external funding.

Institutional Review Board Statement: Not applicable.

Informed Consent Statement: Not applicable.

Data Availability Statement: Data are available in publicly accessible databases. The references of articles included are presented on the reference list and the background data in the Supplementary Material.

Conflicts of Interest: The authors declare no conflict of interest.

\section{References}

1. Virani, S.S.; Alonso, A.; Benjamin, E.J.; Bittencourt, M.S.; Callaway, C.W.; Carson, A.P.; Chamberlain, A.M.; Chang, A.R.; Cheng, S.; Delling, F.N.; et al. Heart Disease and Stroke Statistics-2020 Update: A Report From the American Heart Association. Circulation 2020, 141, e139-e596. [CrossRef] [PubMed]

2. Hindricks, G.; Potpara, T.; Dagres, N.; Arbelo, E.; Bax, J.J.; Blomstrom-Lundqvist, C.; Boriani, G.; Castella, M.; Dan, G.A.; Dilaveris, P.E.; et al. 2020 ESC Guidelines for the diagnosis and management of atrial fibrillation developed in collaboration with the European Association of Cardio-Thoracic Surgery (EACTS). Eur. Heart J. 2020, 42, 373-498. [CrossRef] [PubMed]

3. Kirchhof, P.; Benussi, S.; Kotecha, D.; Ahlsson, A.; Atar, D.; Casadei, B.; Castella, M.; Diener, H.C.; Heidbuchel, H.; Hendriks, J.; et al. 2016 ESC Guidelines for the management of atrial fibrillation developed in collaboration with EACTS. Eur. Heart J. 2016, 37, 2893-2962. [CrossRef] [PubMed]

4. Asad, Z.U.A.; Yousif, A.; Khan, M.S.; Al-Khatib, S.M.; Stavrakis, S. Catheter Ablation Versus Medical Therapy for Atrial Fibrillation. Circ. Arrhythm. Electrophysiol. 2019, 12, e007414. [CrossRef] [PubMed]

5. Kirchhof, P.; Camm, A.J.; Goette, A.; Brandes, A.; Eckardt, L.; Elvan, A.; Fetsch, T.; van Gelder, I.C.; Haase, D.; Haegeli, L.M.; et al. Early Rhythm-Control Therapy in Patients with Atrial Fibrillation. N. Engl. J. Med. 2020, 383, 1305-1316. [CrossRef]

6. Haissaguerre, M.; Jais, P.; Shah, D.C.; Takahashi, A.; Hocini, M.; Quiniou, G.; Garrigue, S.; Le Mouroux, A.; Le Metayer, P.; Clementy, J. Spontaneous initiation of atrial fibrillation by ectopic beats originating in the pulmonary veins. N. Engl. J. Med. 1998, 339, 659-666. [CrossRef]

7. Calkins, H.; Hindricks, G.; Cappato, R.; Kim, Y.H.; Saad, E.B.; Aguinaga, L.; Akar, J.G.; Badhwar, V.; Brugada, J.; Camm, J.; et al. 2017 HRS/EHRA/ECAS/APHRS/SOLAECE expert consensus statement on catheter and surgical ablation of atrial fibrillation: Executive summary. Heart Rhythm 2017, 14, e445-e494. [CrossRef]

8. Murray, M.I.; Arnold, A.; Younis, M.; Varghese, S.; Zeiher, A.M. Cryoballoon versus radiofrequency ablation for paroxysmal atrial fibrillation: A meta-analysis of randomized controlled trials. Clin. Res. Cardiol. 2018, 107, 658-669. [CrossRef]

9. Kabunga, P.; Phan, K.; Ha, H.; Sy, R.W. Meta-Analysis of Contemporary Atrial Fibrillation Ablation Strategies: Irrigated Radiofrequency Versus Duty-Cycled Phased Radiofrequency Versus Cryoballoon Ablation. JACC Clin. Electrophysiol. 2016, 2, 377-390. [CrossRef]

10. Cipriani, A.; Higgins, J.P.; Geddes, J.R.; Salanti, G. Conceptual and technical challenges in network meta-analysis. Ann. Intern. Med. 2013, 159, 130-137. [CrossRef]

11. Dias, S.; Caldwell, D.M. Network meta-analysis explained. Arch. Dis. Child. Fetal Neonatal Ed. 2019, 104, F8-F12. [CrossRef] 
12. Elliott, W.J.; Meyer, P.M. Incident diabetes in clinical trials of antihypertensive drugs: A network meta-analysis. Lancet 2007, 369, 201-207. [CrossRef]

13. Palmerini, T.; Benedetto, U.; Biondi-Zoccai, G.; Della Riva, D.; Bacchi-Reggiani, L.; Smits, P.C.; Vlachojannis, G.J.; Jensen, L.O.; Christiansen, E.H.; Berencsi, K.; et al. Long-Term Safety of Drug-Eluting and Bare-Metal Stents: Evidence From a Comprehensive Network Meta-Analysis. J. Am. Coll. Cardiol. 2015, 65, 2496-2507. [CrossRef]

14. Gupta, D.; Potter, T.; Disher, T.; Eaton, K.; Goldstein, L.; Patel, L.; Grima, D.; Velleca, M.; Costa, G. Comparative effectiveness of catheter ablation devices in the treatment of atrial fibrillation: A network meta-analysis. J. Comp. Eff. Res. 2020, 9, 115-126. [CrossRef]

15. Moher, D.; Liberati, A.; Tetzlaff, J.; Altman, D.G.; Group, P. Preferred reporting items for systematic reviews and meta-analyses: The PRISMA statement. BMJ 2009, 339, b2535. [CrossRef]

16. Charitakis, E.; Karlsson, L.O.; Rizas, K.; Almroth, H.; Hassel Jonsson, A.; Schweiler, J.; Sideris, S.; Tsartsalis, D.; Dragioti, E.; Chaimani, A. Comparing efficacy and safety in catheter ablation strategies for atrial fibrillation: Protocol of a network meta-analysis of randomised controlled trials. BMJ Open 2020, 10, e041819. [CrossRef]

17. European Heart Rhythm, A.; European Association for Cardio-Thoracic, S.; Camm, A.J.; Kirchhof, P.; Lip, G.Y.; Schotten, U.; Savelieva, I.; Ernst, S.; Van Gelder, I.C.; Al-Attar, N.; et al. Guidelines for the management of atrial fibrillation: The Task Force for the Management of Atrial Fibrillation of the European Society of Cardiology (ESC). Eur. Heart J. 2010, 31, 2369-2429. [CrossRef]

18. Sterne, J.A.C.; Savovic, J.; Page, M.J.; Elbers, R.G.; Blencowe, N.S.; Boutron, I.; Cates, C.J.; Cheng, H.Y.; Corbett, M.S.; Eldridge, S.M.; et al. RoB 2: A revised tool for assessing risk of bias in randomised trials. BMJ 2019, 366, 14898. [CrossRef]

19. DerSimonian, R.; Laird, N. Meta-analysis in clinical trials. Control. Clin. Trials 1986, 7, 177-188. [CrossRef]

20. Rücker, G.; Schwarzer, G. Resolve conflicting rankings of outcomes in network meta-analysis: Partial ordering of treatments. Res. Synth. Methods 2017, 8, 526-536. [CrossRef]

21. Higgins, J.P.; Thompson, S.G.; Deeks, J.J.; Altman, D.G. Measuring inconsistency in meta-analyses. BMJ 2003, 327, 557-560. [CrossRef]

22. Chaimani, A.; Higgins, J.P.; Mavridis, D.; Spyridonos, P.; Salanti, G. Graphical tools for network meta-analysis in STATA. PLoS ONE 2013, 8, e76654. [CrossRef]

23. Salanti, G.; Del Giovane, C.; Chaimani, A.; Caldwell, D.M.; Higgins, J.P. Evaluating the quality of evidence from a network meta-analysis. PLoS ONE 2014, 9, e99682. [CrossRef]

24. January, C.T.; Wann, L.S.; Calkins, H.; Chen, L.Y.; Cigarroa, J.E.; Cleveland, J.C., Jr.; Ellinor, P.T.; Ezekowitz, M.D.; Field, M.E.; Furie, K.L.; et al. 2019 AHA/ACC/HRS Focused Update of the 2014 AHA/ACC/HRS Guideline for the Management of Patients With Atrial Fibrillation: A Report of the American College of Cardiology/American Heart Association Task Force on Clinical Practice Guidelines and the Heart Rhythm Society. J. Am. Coll. Cardiol. 2019, 74, 104-132. [CrossRef]

25. Lee, K.N.; Roh, S.Y.; Baek, Y.S.; Park, H.S.; Ahn, J.; Kim, D.H.; Lee, D.I.; Shim, J.; Choi, J.I.; Park, S.W.; et al. Long-Term Clinical Comparison of Procedural End Points After Pulmonary Vein Isolation in Paroxysmal Atrial Fibrillation: Elimination of Nonpulmonary Vein Triggers Versus Noninducibility. Circ. Arrhythm. Electrophysiol. 2018, 11, e005019. [CrossRef]

26. Kiuchi, M.G.; Chen, S.; Hoye, N.A.; Purerfellner, H. Pulmonary vein isolation combined with spironolactone or renal sympathetic denervation in patients with chronic kidney disease, uncontrolled hypertension, paroxysmal atrial fibrillation, and a pacemaker. J. Interv. Card. Electrophysiol. Int. J. Arrhythm. Pacing 2018, 51, 51-59. [CrossRef]

27. Di Biase, L.; Elayi, C.S.; Fahmy, T.S.; Martin, D.O.; Ching, C.K.; Barrett, C.; Bai, R.; Patel, D.; Khaykin, Y.; Hongo, R.; et al. Atrial fibrillation ablation strategies for paroxysmal patients: Randomized comparison between different techniques. Circ. Arrhythm. Electrophysiol. 2009, 2, 113-119. [CrossRef]

28. Chen, M.; Yang, B.; Chen, H.; Ju, W.; Zhang, F.; Tse, H.F.; Cao, K. Randomized comparison between pulmonary vein antral isolation versus complex fractionated electrogram ablation for paroxysmal atrial fibrillation. J. Cardiovasc. Electrophysiol. 2011, 22, 973-981. [CrossRef]

29. Kuck, K.H.; Brugada, J.; Furnkranz, A.; Metzner, A.; Ouyang, F.; Chun, K.R.; Elvan, A.; Arentz, T.; Bestehorn, K.; Pocock, S.J.; et al. Cryoballoon or Radiofrequency Ablation for Paroxysmal Atrial Fibrillation. N. Engl. J. Med. 2016, 374, 2235-2245. [CrossRef]

30. Pappone, C.; Rosanio, S.; Oreto, G.; Tocchi, M.; Gugliotta, F.; Vicedomini, G.; Salvati, A.; Dicandia, C.; Mazzone, P.; Santinelli, V.; et al. Circumferential radiofrequency ablation of pulmonary vein ostia: A new anatomic approach for curing atrial fibrillation. Circulation 2000, 102, 2619-2628. [CrossRef]

31. Bordignon, S.; Chun, K.R.; Gunawardene, M.; Fuernkranz, A.; Urban, V.; Schulte-Hahn, B.; Nowak, B.; Schmidt, B. Comparison of balloon catheter ablation technologies for pulmonary vein isolation: The laser versus cryo study. J. Cardiovasc. Electrophysiol. 2013, 24, 987-994. [CrossRef] [PubMed]

32. Andrade, J.G.; Wells, G.A.; Deyell, M.W.; Bennett, M.; Essebag, V.; Champagne, J.; Roux, J.F.; Yung, D.; Skanes, A.; Khaykin, Y.; et al. Cryoablation or Drug Therapy for Initial Treatment of Atrial Fibrillation. N. Engl. J. Med. 2021, 384, 305-315. [CrossRef] [PubMed]

33. Luik, A.; Radzewitz, A.; Kieser, M.; Walter, M.; Bramlage, P.; Hörmann, P.; Schmidt, K.; Horn, N.; Brinkmeier-Theofanopoulou, M.; Kunzmann, K.; et al. Cryoballoon Versus Open Irrigated Radiofrequency Ablation in Patients With Paroxysmal Atrial FibrillationCLINICAL PERSPECTIVE. Circulation 2015, 132, 1311-1319. [CrossRef] [PubMed] 
34. Perez-Castellano, N.; Fernandez-Cavazos, R.; Moreno, J.; Canadas, V.; Conde, A.; Gonzalez-Ferrer, J.J.; Macaya, C.; PerezVillacastin, J. The COR trial: A randomized study with continuous rhythm monitoring to compare the efficacy of cryoenergy and radiofrequency for pulmonary vein isolation. Heart Rhythm 2014, 11, 8-14. [CrossRef] [PubMed]

35. Dukkipati, S.R.; Neuzil, P.; Kautzner, J.; Petru, J.; Wichterle, D.; Skoda, J.; Cihak, R.; Peichl, P.; Dello Russo, A.; Pelargonio, G.; et al. The durability of pulmonary vein isolation using the visually guided laser balloon catheter: Multicenter results of pulmonary vein remapping studies. Heart Rhythm 2012, 9, 919-925. [CrossRef]

36. Santangeli, P.; Di Biase, L.; Horton, R.; Burkhardt, J.D.; Sanchez, J.; Al-Ahmad, A.; Hongo, R.; Beheiry, S.; Bai, R.; Mohanty, P.; et al. Ablation of atrial fibrillation under therapeutic warfarin reduces periprocedural complications: Evidence from a meta-analysis. Circ. Arrhythm. Electrophysiol. 2012, 5, 302-311. [CrossRef]

37. Santangeli, P.; di Biase, L.; Pelargonio, G.; Natale, A. Outcome of invasive electrophysiological procedures and gender: Are males and females the same? J. Cardiovasc. Electrophysiol. 2011, 22, 605-612. [CrossRef]

38. Dixit, S.; Marchlinski, F.E.; Lin, D.; Callans, D.J.; Bala, R.; Riley, M.P.; Garcia, F.C.; Hutchinson, M.D.; Ratcliffe, S.J.; Cooper, J.M.; et al. Randomized ablation strategies for the treatment of persistent atrial fibrillation: RASTA study. Circ. Arrhythm. Electrophysiol. 2012, 5, 287-294. [CrossRef]

39. Corrado, A.; Bonso, A.; Madalosso, M.; Rossillo, A.; Themistoclakis, S.; Di Biase, L.; Natale, A.; Raviele, A. Impact of systematic isolation of superior vena cava in addition to pulmonary vein antrum isolation on the outcome of paroxysmal, persistent, and permanent atrial fibrillation ablation: Results from a randomized study. J. Cardiovasc. Electrophysiol. 2010, 21, 1-5. [CrossRef]

40. Thiyagarajah, A.; Kadhim, K.; Lau, D.H.; Emami, M.; Linz, D.; Khokhar, K.; Munawar, D.A.; Mishima, R.; Malik, V.; O'Shea, C.; et al. Feasibility, Safety, and Efficacy of Posterior Wall Isolation During Atrial Fibrillation Ablation: A Systematic Review and Meta-Analysis. Circ. Arrhythm. Electrophysiol. 2019, 12, e007005. [CrossRef]

41. Katritsis, D.G.; Pokushalov, E.; Romanov, A.; Giazitzoglou, E.; Siontis, G.C.; Po, S.S.; Camm, A.J.; Ioannidis, J.P. Autonomic denervation added to pulmonary vein isolation for paroxysmal atrial fibrillation: A randomized clinical trial. J. Am. Coll. Cardiol. 2013, 62, 2318-2325. [CrossRef]

42. Steinberg, J.S.; Shabanov, V.; Ponomarev, D.; Losik, D.; Ivanickiy, E.; Kropotkin, E.; Polyakov, K.; Ptaszynski, P.; Keweloh, B.; Yao, C.J.; et al. Effect of Renal Denervation and Catheter Ablation vs Catheter Ablation Alone on Atrial Fibrillation Recurrence Among Patients With Paroxysmal Atrial Fibrillation and Hypertension: The ERADICATE-AF Randomized Clinical Trial. JAMA J. Am. Med. Assoc. 2020, 323, 248-255. [CrossRef]

43. Loring, Z.; Holmes, D.N.; Matsouaka, R.A.; Curtis, A.B.; Day, J.D.; Desai, N.; Ellenbogen, K.A.; Feld, G.K.; Fonarow, G.C.; Frankel, D.S.; et al. Procedural Patterns and Safety of Atrial Fibrillation Ablation: Findings From Get With The Guidelines-Atrial Fibrillation. Circ. Arrhythm. Electrophysiol. 2020, 13, e007944. [CrossRef]

44. Arbelo, E.; Brugada, J.; Blomstrom-Lundqvist, C.; Laroche, C.; Kautzner, J.; Pokushalov, E.; Raatikainen, P.; Efremidis, M.; Hindricks, G.; Barrera, A.; et al. Contemporary management of patients undergoing atrial fibrillation ablation: In-hospital and 1-year follow-up findings from the ESC-EHRA atrial fibrillation ablation long-term registry. Eur. Heart J. 2017, 38, 1303-1316. [CrossRef]

45. Tripathi, B.; Arora, S.; Kumar, V.; Abdelrahman, M.; Lahewala, S.; Dave, M.; Shah, M.; Tan, B.; Savani, S.; Badheka, A.; et al. Temporal trends of in-hospital complications associated with catheter ablation of atrial fibrillation in the United States: An update from Nationwide Inpatient Sample database (2011-2014). J. Cardiovasc. Electrophysiol. 2018, 29, 715-724. [CrossRef]

46. Nattel, S.; Guasch, E.; Savelieva, I.; Cosio, F.G.; Valverde, I.; Halperin, J.L.; Conroy, J.M.; Al-Khatib, S.M.; Hess, P.L.; Kirchhof, P.; et al. Early management of atrial fibrillation to prevent cardiovascular complications. Eur. Heart J. 2014, 35, 1448-1456. [CrossRef]

47. Padfield, G.J.; Steinberg, C.; Swampillai, J.; Qian, H.; Connolly, S.J.; Dorian, P.; Green, M.S.; Humphries, K.H.; Klein, G.J.; Sheldon, R.; et al. Progression of paroxysmal to persistent atrial fibrillation: 10-year follow-up in the Canadian Registry of Atrial Fibrillation. Heart Rhythm 2017, 14, 801-807. [CrossRef]

48. Cosedis Nielsen, J.; Johannessen, A.; Raatikainen, P.; Hindricks, G.; Walfridsson, H.; Kongstad, O.; Pehrson, S.; Englund, A.; Hartikainen, J.; Mortensen, L.S.; et al. Radiofrequency ablation as initial therapy in paroxysmal atrial fibrillation. N. Engl. J. Med. 2012, 367, 1587-1595. [CrossRef]

49. Chen, Y.H.; Lu, Z.Y.; Xiang, Y.; Hou, J.W.; Wang, Q.; Lin, H.; Li, Y.G. Cryoablation vs. radiofrequency ablation for treatment of paroxysmal atrial fibrillation: A systematic review and meta-analysis. Europace 2017, 19, 784-794. [CrossRef]

50. Oral, H.; Scharf, C.; Chugh, A.; Hall, B.; Cheung, P.; Good, E.; Veerareddy, S.; Pelosi, F., Jr.; Morady, F. Catheter ablation for paroxysmal atrial fibrillation: Segmental pulmonary vein ostial ablation versus left atrial ablation. Circulation 2003, 108, 2355-2360. [CrossRef]

51. Katritsis, D.G.; Ellenbogen, K.A.; Panagiotakos, D.B.; Giazitzoglou, E.; Karabinos, I.; Papadopoulos, A.; Zambartas, C.; Anagnostopoulos, C.E. Ablation of superior pulmonary veins compared to ablation of all four pulmonary veins. J. Cardiovasc. Electrophysiol. 2004, 15, 641-645. [CrossRef]

52. Hocini, M.; Jais, P.; Sanders, P.; Takahashi, Y.; Rotter, M.; Rostock, T.; Hsu, L.F.; Sacher, F.; Reuter, S.; Clementy, J.; et al. Techniques, evaluation, and consequences of linear block at the left atrial roof in paroxysmal atrial fibrillation: A prospective randomized study. Circulation 2005, 112, 3688-3696. [CrossRef] 
53. Liu, X.; Dong, J.; Mavrakis, H.E.; Hu, F.; Long, D.; Fang, D.; Yu, R.; Tang, R.; Hao, P.; Lu, C.; et al. Achievement of pulmonary vein isolation in patients undergoing circumferential pulmonary vein ablation: A randomized comparison between two different isolation approaches. J. Cardiovasc. Electrophysiol. 2006, 17, 1263-1270. [CrossRef]

54. Wang, X.H.; Liu, X.; Sun, Y.M.; Shi, H.F.; Zhou, L.; Gu, J.N. Pulmonary vein isolation combined with superior vena cava isolation for atrial fibrillation ablation: A prospective randomized study. Europace 2008, 10, 600-605. [CrossRef]

55. Deisenhofer, I.; Estner, H.; Reents, T.; Fichtner, S.; Bauer, A.; Wu, J.; Kolb, C.; Zrenner, B.; Schmitt, C.; Hessling, G. Does electrogram guided substrate ablation add to the success of pulmonary vein isolation in patients with paroxysmal atrial fibrillation? A prospective, randomized study. J. Cardiovasc. Electrophysiol. 2009, 20, 514-521. [CrossRef]

56. Sawhney, N.; Anousheh, R.; Chen, W.; Feld, G.K. Circumferential pulmonary vein ablation with additional linear ablation results in an increased incidence of left atrial flutter compared with segmental pulmonary vein isolation as an initial approach to ablation of paroxysmal atrial fibrillation. Circ. Arrhythm. Electrophysiol. 2010, 3, 243-248. [CrossRef]

57. Katritsis, D.G.; Giazitzoglou, E.; Zografos, T.; Pokushalov, E.; Po, S.S.; Camm, A.J. Rapid pulmonary vein isolation combined with autonomic ganglia modification: A randomized study. Heart Rhythm 2011, 8, 672-678. [CrossRef]

58. Gavin, A.R.; Singleton, C.B.; Bowyer, J.; McGavigan, A.D. Pulmonary venous isolation versus additional substrate modification as treatment for paroxysmal atrial fibrillation. J. Interv. Card. Electrophysiol. Int. J. Arrhythm. Pacing 2012, 33, 101-107. [CrossRef] [PubMed]

59. Lin, Y.J.; Chang, S.L.; Lo, L.W.; Hu, Y.F.; Suenari, K.; Li, C.H.; Chao, T.F.; Chung, F.P.; Liao, J.N.; Hartono, B.; et al. A prospective, randomized comparison of modified pulmonary vein isolation versus conventional pulmonary vein isolation in patients with paroxysmal atrial fibrillation. J. Cardiovasc. Electrophysiol. 2012, 23, 1155-1162. [CrossRef]

60. Mun, H.S.; Joung, B.; Shim, J.; Hwang, H.J.; Kim, J.Y.; Lee, M.H.; Pak, H.N. Does additional linear ablation after circumferential pulmonary vein isolation improve clinical outcome in patients with paroxysmal atrial fibrillation? Prospective randomised study. Heart 2012, 98, 480-484. [CrossRef]

61. Fichtner, S.; Hessling, G.; Ammar, S.; Reents, T.; Estner, H.L.; Jilek, C.; Kathan, S.; Büchner, M.; Dillier, R.; Deisenhofer, I. A prospective randomized study comparing isolation of the arrhythmogenic vein versus all veins in paroxysmal atrial fibrillation. Clin. Cardiol. 2013, 36, 422-426. [CrossRef] [PubMed]

62. Atienza, F.; Almendral, J.; Ormaetxe, J.M.; Moya, A.; Martinez-Alday, J.D.; Hernandez-Madrid, A.; Castellanos, E.; Arribas, F.; Arias, M.A.; Tercedor, L.; et al. Comparison of radiofrequency catheter ablation of drivers and circumferential pulmonary vein isolation in atrial fibrillation: A noninferiority randomized multicenter RADAR-AF trial. J. Am. Coll. Cardiol. 2014, 64, $2455-2467$. [CrossRef] [PubMed]

63. Kang, K.W.; Pak, H.N.; Park, J.; Park, J.G.; Uhm, J.S.; Joung, B.; Lee, M.H.; Hwang, C. Additional linear ablation from the superior vena cava to right atrial septum after pulmonary vein isolation improves the clinical outcome in patients with paroxysmal atrial fibrillation: Prospective randomized study. Europace 2014, 16, 1738-1745. [CrossRef]

64. Nuhrich, J.M.; Steven, D.; Berner, I.; Rostock, T.; Hoffmann, B.; Servatius, H.; Sultan, A.; Luker, J.; Treszl, A.; Wegscheider, K.; et al. Impact of biatrial defragmentation in patients with paroxysmal atrial fibrillation: Results from a randomized prospective study. Heart Rhythm 2014, 11, 1536-1542. [CrossRef]

65. Arbelo, E.; Guiu, E.; Ramos, P.; Bisbal, F.; Borras, R.; Andreu, D.; Tolosana, J.M.; Berruezo, A.; Brugada, J.; Mont, L. Benefit of left atrial roof linear ablation in paroxysmal atrial fibrillation: A prospective, randomized study. J. Am. Heart Assoc. 2014,3 , e000877. [CrossRef]

66. Faustino, M.; Pizzi, C.; Agricola, T.; Xhyheri, B.; Costa, G.M.; Flacco, M.E.; Capasso, L.; Cicolini, G.; Di Girolamo, E.; Leonzio, L.; et al. Stepwise ablation approach versus pulmonary vein isolation in patients with paroxysmal atrial fibrillation: Randomized controlled trial. Heart Rhythm 2015, 12, 1907-1915. [CrossRef]

67. Da Costa, A.; Levallois, M.; Romeyer-Bouchard, C.; Bisch, L.; Gate-Martinet, A.; Isaaz, K. Remote-controlled magnetic pulmonary vein isolation combined with superior vena cava isolation for paroxysmal atrial fibrillation: A prospective randomized study. Arch. Cardiovasc. Dis. 2015, 108, 163-171. [CrossRef]

68. Kim, T.H.; Park, J.; Park, J.K.; Uhm, J.S.; Joung, B.; Hwang, C.; Lee, M.H.; Pak, H.N. Linear ablation in addition to circumferential pulmonary vein isolation (Dallas lesion set) does not improve clinical outcome in patients with paroxysmal atrial fibrillation: A prospective randomized study. Europace 2015, 17, 388-395. [CrossRef]

69. Gaita, F.; Caponi, D.; Scaglione, M.; Montefusco, A.; Corleto, A.; Di Monte, F.; Coin, D.; Di Donna, P.; Giustetto, C. Long-term clinical results of 2 different ablation strategies in patients with paroxysmal and persistent atrial fibrillation. Circ. Arrhythm. Electrophysiol. 2008, 1, 269-275. [CrossRef]

70. Bulava, A.; Hanis, J.; Sitek, D.; Osmera, O.; Karpianus, D.; Snorek, M.; Rehouskova, K.; Tousek, F.; Pesl, L. Catheter ablation for paroxysmal atrial fibrillation: A randomized comparison between multielectrode catheter and point-by-point ablation. Pacing Clin. Electrophysiol. 2010, 33, 1039-1046. [CrossRef]

71. McCready, J.; Chow, A.W.; Lowe, M.D.; Segal, O.R.; Ahsan, S.; de Bono, J.; Dhaliwal, M.; Mfuko, C.; Ng, A.; Rowland, E.R.; et al. Safety and efficacy of multipolar pulmonary vein ablation catheter vs. irrigated radiofrequency ablation for paroxysmal atrial fibrillation: A randomized multicentre trial. Europace 2014, 16, 1145-1153. [CrossRef] 
72. Hunter, R.J.; Baker, V.; Finlay, M.C.; Duncan, E.R.; Lovell, M.J.; Tayebjee, M.H.; Ullah, W.; Siddiqui, M.S.; Mc, L.A.; Richmond, L.; et al. Point-by-Point Radiofrequency Ablation Versus the Cryoballoon or a Novel Combined Approach: A Randomized Trial Comparing 3 Methods of Pulmonary Vein Isolation for Paroxysmal Atrial Fibrillation (The Cryo Versus RF Trial). J. Cardiovasc. Electrophysiol. 2015, 26, 1307-1314. [CrossRef]

73. McLellan, A.J.; Ling, L.H.; Azzopardi, S.; Lee, G.A.; Lee, G.; Kumar, S.; Wong, M.C.; Walters, T.E.; Lee, J.M.; Looi, K.L.; et al. A minimal or maximal ablation strategy to achieve pulmonary vein isolation for paroxysmal atrial fibrillation: A prospective multi-centre randomized controlled trial (the Minimax study). Eur. Heart J. 2015, 36, 1812-1821. [CrossRef]

74. Podd, S.J.; Sulke, A.N.; Sugihara, C.; Furniss, S.S. Phased multipolar radiofrequency pulmonary vein isolation is as effective and safe as conventional irrigated point-to-point ablation. A prospective randomised 1-year implantable cardiac monitoring device follow-up trial. J. Interv. Card. Electrophysiol. Int. J. Arrhythm. Pacing 2015, 44, 257-264. [CrossRef]

75. Boersma, L.V.; van der Voort, P.; Debruyne, P.; Dekker, L.; Simmers, T.; Rossenbacker, T.; Balt, J.; Wijffels, M.; Degreef, Y. Multielectrode Pulmonary Vein Isolation Versus Single Tip Wide Area Catheter Ablation for Paroxysmal Atrial Fibrillation: A Multinational Multicenter Randomized Clinical Trial. Circ. Arrhythm. Electrophysiol. 2016, 9, e003151. [CrossRef]

76. Schirdewan, A.; Herm, J.; Roser, M.; Landmesser, U.; Endres, M.; Koch, L.; Haeusler, K.G. Loop Recorder Detected High Rate of Atrial Fibrillation Recurrence after a Single Balloon- or Basket-Based Ablation of Paroxysmal Atrial Fibrillation: Results of the MACPAF Study. Front. Cardiovasc. Med. 2017, 4, 4. [CrossRef]

77. Davtyan, K.; Shatakhtsyan, V.; Poghosyan, H.; Deev, A.; Tarasov, A.; Kharlap, M.; Serdyuk, S.; Simonyan, G.; Boytcov, S. Radiofrequency versus Cryoballoon Ablation of Atrial Fibrillation: An Evaluation Using ECG, Holter Monitoring, and Implantable Loop Recorders to Monitor Absolute and Clinical Effectiveness. BioMed Res. Int. 2018, 2018, 3629384. [CrossRef]

78. Kircher, S.; Arya, A.; Altmann, D.; Rolf, S.; Bollmann, A.; Sommer, P.; Dagres, N.; Richter, S.; Breithardt, O.A.; Dinov, B.; et al Individually tailored vs. standardized substrate modification during radiofrequency catheter ablation for atrial fibrillation: A randomized study. Europace 2018, 20, 1766-1775. [CrossRef]

79. You, L.; Yao, L.; Zhou, B.; Jin, L.; Yin, H.; Wu, J.; Yin, G.; Yang, Y.; Zhang, C.; Liu, Y.; et al. Effects of different ablation strategies on long-term left atrial function in patients with paroxysmal atrial fibrillation: A single-blind randomized controlled trial. Sci. Rep. 2019, 9, 7695. [CrossRef]

80. Giannopoulos, G.; Kossyvakis, C.; Vrachatis, D.; Aggeli, C.; Tsitsinakis, G.; Letsas, K.; Tsiachris, D.; Tsoukala, S.; Efremidis, M.; Katritsis, D.; et al. Effect of cryoballoon and radiofrequency ablation for pulmonary vein isolation on left atrial function in patients with nonvalvular paroxysmal atrial fibrillation: A prospective randomized study (Cryo-LAEF study). J. Cardiovasc. Electrophysiol. 2019, 30, 991-998. [CrossRef]

81. Andrade, J.G.; Champagne, J.; Dubuc, M.; Deyell, M.W.; Verma, A.; Macle, L.; Leong-Sit, P.; Novak, P.; Badra-Verdu, M.; Sapp, J.; et al. Cryoballoon or Radiofrequency Ablation for Atrial Fibrillation Assessed by Continuous Monitoring: A Randomized Clinical Trial. Circulation 2019, 140, 1779-1788. [CrossRef] [PubMed]

82. Pappone, C.; Augello, G.; Sala, S.; Gugliotta, F.; Vicedomini, G.; Gulletta, S.; Paglino, G.; Mazzone, P.; Sora, N.; Greiss, I.; et al. A randomized trial of circumferential pulmonary vein ablation versus antiarrhythmic drug therapy in paroxysmal atrial fibrillation: The APAF Study. J. Am. Coll. Cardiol. 2006, 48, 2340-2347. [CrossRef] [PubMed]

83. Sohara, H.; Ohe, T.; Okumura, K.; Naito, S.; Hirao, K.; Shoda, M.; Kobayashi, Y.; Yamauchi, Y.; Yamaguchi, Y.; Kuwahara, T.; et al. HotBalloon Ablation of the Pulmonary Veins for Paroxysmal AF: A Multicenter Randomized Trial in Japan. J. Am. Coll. Cardiol. 2016, 68, 2747-2757. [CrossRef] [PubMed] 